\title{
Musicalidade comunicativa e senso de eu
}

\author{
Communicative musicality and sense of self
}

Leda de Albuquerque Maffioletti*

leda.maffioletti@gmail.com

* Professora Associada da Universidade Federal do Rio Grande do Sul (UFRGS). Atuou como professora no curso de Pedagogia e Programa de Pós-Graduação. Especialista em Psicopedagogia Clínica no EPISIBA - Escuela de Psicopedagogia de Buenos Aires. Doutora em Educação pela UFRGS. 


\section{Resumo}

Este artigo apresenta um estudo teórico sobre o conceito de musicalidade comunicativa proposto por Malloch (1999), Malloch e Trevarthen (2009), e o de senso de eu, conforme defende Daniel Stern (1992-2000), com o objetivo de aprofundar a compreensão sobre a natureza das relações que o ser humano estabelece com a música. A estratégia consiste em estabelecer um diálogo com alguns pesquisadores, articulando suas ideias na compreensão do tema proposto. Conclui-se que as relações intersubjetivas são o ponto comum que articula os dois conceitos. Na musicalidade comunicativa, elas são responsáveis pela estrutura emocional que garante a experiência musical compartilhada; na formação do senso de eu e sua contrapartida, eu com o outro criam possibilidades de aprendizagem, dentre elas, a possibilidade de um senso de eu musical ou uma possibilidade de identidade musical.

Palavras-chave: Musicalidade comunicativa; Senso de eu; Processos intersubjetivos

\section{Abstract}

This article presents a theoretical study about the following concepts: communicative musicality as proposed by Malloch (1999) and Malloch and Trevarthen (2009), and the sense of self put forward by Daniel Stern (1992-2000), with a purpose of further understanding the nature of human beings' relations with music. The strategy herein consists of establishing a conversation with a few researchers and articulating their ideas in order to understand the theme proposed. The conclusion asserts that intersubjective relations form a common point that expresses both concepts. In communicative musicality, intersubjective relations are responsible for the emotional structure that guarantees shared musical experience; in forming the sense of self and its counterpart self with others, intersubjective relations create learning possibilities, including that of a musical sense of self or musical identity.

Keywords: Communicative musicality. Sense of self. Intersubjective processes. 


\section{Introdução}

Quando você viaja para um país estranho e não compreende a língua, a expressão facial, os movimentos dos olhos e das sobrancelhas, os gestos, o tom de voz e a melodia da fala passam a ser as pistas mais importantes de comunicação. Acreditando que essa é uma forma eficiente de comunicação, você também a emprega para se fazer entender.

Diante de um bebê de poucos meses, os adultos também modificam o modo usual de falar, sacodem a cabeça, dizem "oh!!!", fazem barulhos com a boca... Geralmente dá certo, os bebês ficam embevecidos e correspondem amistosamente.

Conforme argumentam os autores Malloch e Trevarthen (2009), até a década de 1960, a Medicina e a Psicologia não viam em cenas como essa algo que merecesse um estudo sério, porque a criança era considerada um ser incapaz e totalmente dependente dos cuidados dos adultos; o papel da mãe limitava-se aos cuidados físicos de alimentação, sono e higiene. Porém, os pesquisadores que se afastaram dessa concepção se interessavam pelos problemas práticos da comunicação humana e pelo processamento da informação cognitiva da linguagem. Os problemas práticos da comunicação, como a sintonia de interesses e a compreensão dos significados, estavam claramente presentes nas trocas afetivas dos bebês com suas mães. Por essa razão, os bebês passaram a ser considerados mais conscientes da presença humana, responsivos e abertos aos diálogos com suas mães. As mães, por sua vez, foram consideradas hábeis na tarefa de capturar o fluxo das trocas afetivas.

Mas o que o diálogo mãe-bebê tem a ver com a comunicação entre os adultos? Beebe et al. (1988) defendem que a conversa em forma de diálogo coordenado em turnos é logicamente os fundamentos da linguagem. Os autores esclarecem que o diálogo entre os adultos se define por uma estrutura temporal que combina turnos de voz e silêncio. Essa estrutura compartilhada é sentida como congruência vocal. A par dessa congruência, sentimentos relacionados a si mesmo são formados como correlatos afetivos da congruência vocal. Conforme a conversa se desenrola e esses parâmetros são seguidos, os parceiros avaliam seus processos interpessoais e afetivos de acordo com o grau de prazer no contato social. Na pesquisa desenvolvida pelos autores, que enfocou a congruência vocal no diálogo mãe-bebê, o mesmo fenômeno foi constatado. Os padrões temporais das trocas vocais, inclusive sobre o papel do silêncio, foram semelhantes aos que ocorrem no diálogo entre os adultos. Em acréscimo, os correlatos afetivos que costumam aparecer nos diálogos dos adultos também aparecem nos diálogos mãe-bebê. A conclusão dessa pesquisa evidenciou que a estrutura temporal que dá sustentação ao diálogo está presente desde o início de forma semelhante à conversa dos adultos. Os bebês são sensíveis às sequências temporais e alteram seu comportamento para ajustá-lo à estrutura temporal do diálogo. A coordenação que gera a congruência vocal não é da responsabilidade exclusiva da mãe, mas da ação controlada de ambos.

A estrutura temporal da experiência evidenciada nas interações dos bebês também foi um aspecto intrigante nos estudos de Michel Imberty (2008). Dois questionamentos chamaram sua atenção: "A narrativa estrutura a experiência humana do tempo, mas ela também estrutura e organiza a nossa experiência com a música? [...] Poderia a músi- 
ca, em virtude de sua temporalidade, ser uma forma de narrativa?" (p. 129-130)1. Com base no aporte teórico de Daniel Stern, Imberty analisa os elementos que estruturam a conversa das mães com seus bebês, constatando que os sentimentos que emergem no diálogo expressam uma intenção comunicativa orientada pelo prazer de compartilhar o tempo vivido. A estrutura dessa experiência é de natureza protonarrativa, a partir da qual o bebê sente sua própria experiência como relacionada às suas percepções e sentimentos experimentados no diálogo. O contorno vocal, ou a melodia de sua voz, traça de forma não verbal as linhas das histórias pessoais e íntimas, que mais tarde serão colocadas em palavras. "A estrutura proto-narrativa é, portanto, fundamentalmente musical porque é, de modo substancial, som e ritmo, acento e modulação expressiva" (IMBERTY, 2008, p. 132). ${ }^{2}$

Ellen Dissanayake (2017) observou que os estudiosos da evolução humana reconhecem que o bebê humano, diferentemente de outras espécies, depende dos cuidados de um adulto por um tempo bem prolongado. Esse período de convivência e participação em atividades socioculturais na família e na comunidade promove aprendizagens fundamentais ao ser humano, como a capacidade de comunicação com o outro de modo eficiente e ser capaz de atitudes colaborativas.

As práticas sociais envolvendo a música, principalmente as que envolvem sincronia no tempo (canto em conjunto e ritmo), potencializam o envolvimento futuro do bebê em jogos cooperativos, não só na área da música, mas em outras áreas em que essa capacidade seja necessária, conforme comprovam as pesquisas de Kirschner e Tomasello (2010).

Os estudos que enfocam as habilidades sociais das crianças deixam claro que os bebês vêm ao mundo prontos para se envolverem em trocas interativas com as pessoas ao seu redor. Esta predisposição seria o início da musicalidade a ser desenvolvida, mediante a participação em grupos, situações e instituições sociais de uma cultura particular, onde são negociados e incorporados os fatores socioculturais que caracterizam as identidades musicais (HARGREAVES; MACDONALD; MIELL, 2012). De acordo com Barrett (2016), o engajamento da criança pequena em atividades interativas pode ser considerado fundamental na constituição de sua identidade musical.

A linha argumentativa do presente artigo valoriza de modo especial o movimento, o tempo, a energia, o espaço e as intenções, que juntos constituem a visão holística na experiência humana, conforme defende Stern (2010). A compreensão de alguns conceitos desse autor podem ser promissores na complementação do conceito de "musicalidade comunicativa" proposto por Stephen Malloch (1999) e Stephen Malloch e Colwyn Trevarthen (2009).

Trata-se de um ensaio teórico que aproxima conceitos das áreas de Música e de Psicanálise para refletir sobre a natureza das relações que o ser humano estabelece com a música. Compreendo que [...] as experiências com a música são cruciais, porque

\footnotetext{
1 "Narrative structures the human experience of time, but does it also organize our musical experience? [...] Could music, by virtue of its temporality, be a form of narrative?"

2 "The proto-narrative envelope is thus fundamentally musical because it is in substance sound and rhythm, accent and expressive modulation."
} 
incorporam a regularidade, a previsibilidade e a coerência necessárias para entender as relações sociais" (MAFFIOLETTI, 2011, p. 70).

Enfocando a educação musical de crianças bem pequenas, não se pode deixar de sublinhar que o aparecimento precoce das habilidades musicais ocorre juntamente a outras aprendizagens primárias do ser humano, como aprender a se alimentar, expressar emoções básicas, andar e falar. Por estar presente nos momentos em que a criança adquire as aprendizagens essenciais à sua natureza humana, a música tem a mesma força e significado da aprendizagem da língua maternal (MAFFIOLETTI, 2014). Este é o contexto a partir do qual as reflexões do presente artigo poderão qualificar as propostas de educação musical oferecidas às crianças pequenas.

Nas seções "Musicalidade comunicativa: um conceito abrangente de comunicação humana" e "Senso de eu: a subjetividade que organiza a experiência humana", apresento os conceitos principais e procuro articular as duas concepções teóricas, estabelecendo relações de complementariedade que me pareceram promissoras na compreensão das relações intersubjetivas que caracterizam a emergência de um eu musical.

Como fechamento das ideias deste artigo, procuro dar visibilidade ao conceito de musicalidade comunicativa e senso de eu, mostrando, através de um exercício teórico-prático (análise de uma interação mãe-bebê), de que modo percebo a integração dos conceitos desenvolvidos ao longo do texto.

\section{Musicalidade Comunicativa: um conceito abrangente de comunicação humana}

As relações interpessoais dos bebês com seus familiares não é um assunto novo. Todos nós temos alguma coisa para contar sobre o que os bebês são capazes de fazer. Há centenas de vídeos postados no YouTube de bebês menores de 3 meses tentando imitar o que ouvem e reagindo de forma expressiva aos diálogos com seus pais. Pesquisadores de várias áreas (Psicologia, Psiquiatria, Música, Sociologia, Linguística, Antropologia, Biologia e outras) acreditam nas potencialidades dos bebês e investem na compreensão de seus gestos expressivos.

Para iniciar esta seção, convido os leitores a assistirem ao vídeo "Still Face Experiment: Dr. Edward Tronick"3, com duração de 2'48", disponível no YouTube (vide rodapé). O vídeo apresenta um bebê de aproximadamente cinco meses em diálogo face a face com sua mãe e enfoca a receptividade do bebê às emoções e interações sociais.

Em poucas palavras: a mãe inicia o diálogo com o bebê segurando-lhe as mãos, balançando suavemente seus braços enquanto diz frases curtas e expressões de afeto diretamente dirigidas a ele. $O$ bebê mostra entender a brincadeira, sorri e corresponde às expressões da mãe; aponta indicando para determinado lugar no espaço, a mãe corresponde olhando para onde ele indica, fazendo-lhe cócegas da ponta do pé até a barriga e o bebê se retorce em sorrisos. O diálogo que se estabelece ocorre de maneira coordenada e fluente. Em certo momento, conforme fora acordado previamente com Dr. Tronick, a mãe passa a não interagir com seu bebê. Seu rosto muda de expressão, não reage às 
interações do bebê, não faz nenhuma outra expressão, apenas permanece imóvel, neutra, diante dele. $O$ bebê percebe imediatamente a mudança e fica desapontado, tenta de todas as formas restabelecer o diálogo. Sorri e repete o que havia feito segundos atrás, aponta para certo lugar e exclama "da... da... da...", bate palmas, mas a mãe não reage. $O$ bebê olha para os lados, junta as mãos e aperta, levando-as até a boca; por fim, agita-se na cadeira e grita em tom agudo e começa a chorar. A cena dura quatro segundos, quando então a mãe restabelece o diálogo e tudo volta a ser como antes.

Embora seja uma experiência realizada em estúdio, o bebê mostra capacidade para entender expressões faciais, sons e gestos que ocorrem durante as interações com sua mãe. Corresponde com sorrisos e expressões de alegria; mostra desconforto e insegurança quando não é correspondido e se esforça para sustentar o diálogo.

As expressões a que assistimos no vídeo, como sorrir, evitar olhar, vocalizações, flashes de reconhecimento, gestos que transmitem desconforto ou prazer, imitações, já foram constatados pelos pesquisadores em bebês com poucas semanas de vida (TREVARTHEN; AITKEN, 2001), evidenciando que o bebê nasce com predisposição biológica para as aprendizagens culturais.

A relação mãe-bebê tem sido analisada sob diferentes perspectivas. Anne Fernald e Thomas Simon (1984) publicaram os resultados de sua pesquisa sobre a prosódia característica da conversa das mães com seus bebês, conhecida como motherese ${ }^{4}$ ou baby tolk, traduzida para o português como mamanhês ou manhês.

A partir de observações e análise de gravações em vídeo, os pesquisadores descreveram as características principais do mamanhês e sua relação com a compreensão da intencionalidade da comunicação. As conclusões mostraram que a característica da emissão dos sons e os acentos da voz é distinta da fala entre adultos. Na relação mãe-bebê, normalmente os sons são mais exagerados, as falas são em tom mais agudo e o tempo mais lento ao pronunciar as palavras; há incidência de repetições constantes. Conforme os autores assinalam, as variações melódicas carregam mensagens distintas de admiração, de dúvida ou de alegria, que ajudam a criança a compreender o significado da mensagem presente no discurso das mães. Por exemplo, para acalmar o bebê ou diminuir a excitação, as vocalizações são suaves. Porém, para fazer alguma advertência, inibir comportamentos ou chamar a atenção para algum perigo, as vocalizações são mais curtas e nítidas, com voz mais grave que os vocalizes de conforto. A repetição constante de padrões melódicos e rítmicos são essenciais para que o bebê reconheça e identifique o significado. A pesquisa posterior (FERNALD, 1985) comprovou que os bebês de quatro meses preferem ouvir o mamanhês que qualquer outra sonoridade feita pela mãe.

O estudo de maior impacto sobre esse tema no meio científico foi, sem dúvida, as pesquisas de Stephen Malloch (1999) e Malloch e Trevarthen (2009), pela análise detalhada da qualidade sonora das vocalizações. Examinando as interações dos bebês em diálogos afetuosos com seus pais ou com outras pessoas, os pesquisadores observaram que eles não só imitam as sonoridades, mas participam dos padrões rítmicos coordenados que acompanham as vocalizações. 
Aproveitando os recursos de um software, os pesquisadores analisaram três elementos básicos da comunicação mãe-bebê: o pulso, que compreende os intervalos regulares de tempo que servem para coordenar as vocalizações; a qualidade, que envolve o tom das vocalizações, contorno melódico e timbres; e a narrativa, que combina pulso e qualidade, permitindo que duas pessoas compartilhem o tempo e os significados de maneira conjunta.

A compreensão que Malloch (1999) e Malloch e Trevarthen (2009) construíram a partir de seus estudos fundamentou a teoria da musicalidade comunicativa, que regula o modo como os elementos básicos (pulso, qualidade e narrativa) criam os padrões da comunicação. A musicalidade comunicativa torna possível compartilhar o tempo de forma significativa; sua riqueza emocional possibilita a apreciação e a produção de uma infinidade de variadas narrativas.

As respostas sensíveis dos bebês a diferentes entonações da voz humana e seu engajamento em padrões rítmicos, improvisações e imitações representam uma verdadeira "música" ou certos tipos de "dança", cujo significado não verbal é compartilhado espontaneamente pelas pessoas à sua volta. A energia presente na entonação da comunicação é nomeada por Malloch e Trevarthen como musicalidade comunicativa. A musicalidade a que eles se referem tem sentido particular, é uma musicalidade sutil, sensível, presente no ser humano como uma habilidade inata para a comunicação e para as aprendizagens culturais.

As características musicais dos vocalizes dos bebês foram compreendidas por Hannuš Papušek (2000) como a expressão evidente da musicalidade humana desde o início da vida. Da mesma forma, a canção de ninar, de características muito semelhantes, é uma prática cultural que ocorre em momentos de intimidade afetiva das mães com seus bebês. Do seu ponto de vista, a cultura, a música e a linguagem estão continuamente presentes ao longo da história da humanidade, derivando-se dessa constatação a relevância da música na infância.

Os pesquisadores que analisam a relação mãe-bebê argumentam que os movimentos, expressões faciais e os gestos empregados nessa relação estão presentes de modo inconsciente nos discursos dos adultos quando conversam com seus pares. A antropóloga Ellen Dissanayake (2001 e 2012) comparou as características do mamanhês aos padrões melódicos e ritmos presentes nos rituais de diferentes povos, chegando a conclusões semelhantes. Tanto nos rituais como nos encontros entre pessoas adultas que compartilham significados culturais, os movimentos do corpo para frente e para trás, as frases repetitivas, o movimento das sobrancelhas, os olhos arregalados, os gritos em tom agudo, tal como Ferland e Simon (1984) haviam constatado na relação mãe-bebê, são expressões importantes também nas relações sociais entre os adultos e são interpretadas culturalmente como expressões de afeto, alegria, surpresa ou medo e suspense. Baseada em seus estudos antropológicos, Dissanayake afirma que as primeiras narrativas eram musicais.

Uma vez apresentados os argumentos teóricos que fundamentam o conceito de musicalidade comunicativa e sua relevância na expressão e apreensão de significados compartilhados socialmente, a seção a seguir expõe os fundamentos do senso de eu e sua relevância na constituição do ser social. 


\section{Senso de eu: a subjetividade que organiza a experiência humana}

A maioria dos pesquisadores citados anteriormente faz referência a Daniel Stern, psiquiatra infantil conhecido entre nós principalmente pelas obras O Diário de um bebê. O que seu filho vê e sente (1991) e O mundo interpessoal do bebê (1992). O maior proveito dos aportes de Stern diz respeito às primeiras experiências do bebê e ao modo como as experiências subjetivas compartilhadas no diálogo mãe-bebê formam no bebê o senso de eu. Esse argumento é especialmente importante se considerarmos que as relações intersubjetivas que nutrem a musicalidade comunicativa encontram ressonâncias nos processos de constituição do Eu, como veremos adiante.

Daniel Stern (2000) utiliza a metáfora da música para pensar a experiência da criança pequena. Assim como a música, a experiência também ocorre no tempo, tanto no tempo subjetivo como tempo físico. As atividades dos bebês, como vocalizações, gestos, expressões faciais, movimentos corporais, todas têm duração. Sendo a música e o tempo duas experiências muito comuns, seria muito interessante compreender a capacidade dos bebês, para perceber e discriminar as características temporais da experiência, mais precisamente, da experiência vivida com a música.

No primeiro ano de vida, boa parte das interações dos bebês com os pais está ligada ao atendimento de suas necessidades psicofisiológicas de alimentação e sono. Esses momentos são marcados por comportamentos e frases repetitivas que, embora não sejam sempre as mesmas palavras ditas do mesmo modo, são cenas que ajudam o bebê a se situar no tempo do momento presente.

Stern observou que a psicologia em geral e principalmente a psicanálise tendem a considerar que as experiências vividas no momento presente tomam forma depois que acontecem, quando são reconstruídas simbolicamente ou verbalmente. Discordando dessa posição teórica, o autor defende que os bebês, apesar de não possuírem os requisitos mínimos para criar estruturas ou formas a partir de representações, são capazes de construir a forma ou o contorno temporal de suas experiências durante os acontecimentos que se desenrolam no momento presente.

Comparando a experiência dos bebês com a experiência de alguém que ouve uma frase musical pela primeira vez, a apreensão da forma da melodia precisa ser entendida enquanto está ocorrendo, e não depois, porque a segunda frase é imediatamente iniciada. A nova frase pode, inclusive, modificar o sentido da primeira frase ou suscitar novas expectativas de como será a sua continuidade. Para que esse processo se desenrole, a memória e a representação são acionadas no tempo presente, no momento vivido daquele instante.

O tempo da experiência vivida no momento presente, tal como Stern o concebe, não pode ser compreendido como um tempo físico linear e sequencial, identificado como um antes, o agora e o depois. É preciso compreendê-lo no sentido fenomenológico, conforme defende o filósofo Edmund Husserl em sua obra sobre a consciência interna do tempo. Ou seja, o tempo presente, em si, é formado de um tempo infinitamente mínimo, em constante movimento, que tem a duração de um evento unitário formado por uma sequência de instantes enquanto se movimenta. Stern explica que 
o momento presente se compõe em três partes: o primeiro é o "ponto instantâneo ou móvel do presente"; o segundo é o "passado imediato do momento presente" e o terceiro é "o futuro imediato do momento presente". Assim compreendidos, os eventos que ocorrem no momento atual "recebem uma forma inicial à medida que são experimentados" (STERN, 2000, p, 24) . $^{5}$

Do mesmo modo como a frase musical é capturada pelo ouvinte à medida que o passado imediato ainda ressoa no momento presente, em direção ao futuro imediato, as estruturas do tempo são apreendidas à medida que se desdobram no tempo. Um aspecto importante na concepção de experiência defendido por Stern é que se uma forma temporal e um sentido musical podem ser criados no momento presente, as construções que ocorrem após as experiências vividas não precisam ser criadas, mas revisadas ou reorganizadas. Sendo o momento presente formado por um tempo mínimo, há revisões primárias ocorrendo durante o momento presente. A partir das características que formam o momento presente, o autor defende que a criança pequena não precisa de um processo verbal simbólico para atribuir sentido à experiência imediata que está acontecendo no momento presente.

O senso de eu, na abordagem de Stern (1992), refere-se ao eu da experiência direta, como consciência simples, não autorreflexiva, nem como conceito. Trata-se de um eu invariante que surge apenas no momento das ações, como experiência subjetiva organizadora do momento presente.

A experiência subjetiva do eu organizador reúne de forma unificadora os sons, movimentos, sensações, toques, visões e sentimentos separados. Todos esse eventos, embora separados e fora da consciência, tornam-se familiares e são experimentados como senso de eu.

As perspectivas subjetivas que organizam os comportamentos e as capacidades novas dos bebês propiciam diferentes sensos de eu em relação ao outro. Sendo assim, há diferentes sensos de eu (eu emergente, eu nuclear, eu subjetivo e eu verbal) que descrevem os domínios da autoexperiência.

O senso de eu e sua contraparte, o senso do outro,

[...] são fenômenos universais que influenciam profundamente todas as nossas experiências sociais [...] O modo como experienciamos a nós mesmos em relação aos outros oferece uma perspectiva organizadora básica para todos os eventos interpessoais. (STERN, 1992, p. 3).

Ao se referir às conquistas dos bebês, é do ser humano em geral que Stern está tratando. Suas explicações nos permitem avançar na compreensão do que nos caracteriza como seres humanos. O ponto de origem do ser social que somos encontra sentido na interdependência mútua entre senso de eu e sua contraparte, o senso do outro. 


\section{Conclusões}

\section{Tornando visível a musicalidade comunicativa e o senso de eu musical}

Encaminhando as conclusões deste artigo, depreende-se do aporte teórico de Daniel Stern (2000 e 1992) que a estrutura temporal que configura a musicalidade comunicativa é uma experiência vivida no momento presente, criada e renovada continuamente a cada vez que uma nova perspectiva subjetiva reorganiza as experiências dos diferentes sensos de eu. Sendo assim, podemos admitir que tais estruturas realmente existem, embora lhes falte o sistema simbólico e representativo próprio das aquisições mais complexas.

Os aportes teóricos de Malloch (1999), Malloch e Trevarten (2009) e Stern (2000 e 1992) permitem supor que a musicalidade comunicativa, em razão do espaço intersubjetivo que ela produz, enseja também a produção do senso de eu musical, que se mostra na expressividade motora, na intencionalidade dos gestos e da entonação vocal. As estruturas temporais experimentadas, os ciclos crescentes e decrescentes das canções e brincadeiras interativas regulam a autoexperiência do bebê e, simultaneamente, oferecem novas perspectivas para todos os eventos interpessoais.

Trevarthen e Delafield-Butt (2017) complementam essa ideia defendendo que não só as vocalizações dos bebês, mas também os jogos motores e as canções das crianças pequenas apresentam as características da musicalidade comunicativa. Para dar maior visibilidade a esse conceito e à sua compreensão como instância da constituição do eu musical, proponho que analisemos um diálogo onde tais características ocorrem.

Como exercício teórico-prático que busca articular os conceitos trabalhados, aproveito um episódio capturado do texto de Malloch (1999, p. 46), em que a musicalidade comunicativa favorece o desenrolar de uma narrativa com início, meio e fim. $O$ recorte escolhido apresenta uma estrutura protonarrativa, podendo ser considerado, nos termos de Imberty (2008), uma narrativa musical.

Trata-se da reprodução gráfica dos vocalizes de uma menina de quatro meses que interage com sua mãe em ambiente familiar, enquanto cantam uma canção já conhecida (Clap-a-cap-a- handies). Na figura a seguir, a linha de cima representa a voz da mãe, a linha de baixo, a voz do bebê. Conforme discriminado anteriormente, Malloch (1999) analisou os intervalos regulares de tempo que coordenam as vocalizações; o tom e o contorno das vocalizações e a narrativa compartilhada. Os traços verticais ou barras não representam os compassos musicais, mas cumprem o papel de identificar a estrutura do diálogo mãe-bebê.

A transcrição abaixo é uma tradução livre, com adaptações a partir do original (p. 45-46):

Assim que a mãe começa a cantar, o bebê sorri e mostra sinais de prazer. No primeiro verso, o bebê não vocaliza e foi omitido no gráfico. No segundo verso, a mãe substitui a letra da canção por "di dum. di dum. di dum", representado por figuras rítmicas. O tempo de duração é indicado em segundos acima da barra. No segundo verso, podemos ver que o bebê participa da canção e mostra variedade e consistência rítmica. 
Malloch chama a atenção para o uso que o bebê faz de anacruse no segundo verso; na segunda e terceira barras, o bebê fala no ritmo; na terceira barra, o bebê introduz uma ideia nova em quiáltera, e sorri nesse momento. No terceiro verso, Malloch novamente chama a atenção para o bebê, que sempre vocaliza na última batida de cada barra, como um anacruse para o verso seguinte. Parece que o bebê está mudando seu estilo. $\mathrm{Na}$ terceira barra do terceiro verso, o bebê faz o que Malloch chamou de "piada musical", pois a figura de uma semicolcheia é feita com ênfase, como se quisesse enfatizar que pretende antecipar o tempo. Logo após essa ênfase, mamãe e bebê riem juntos e a rima a seguir perde a energia.

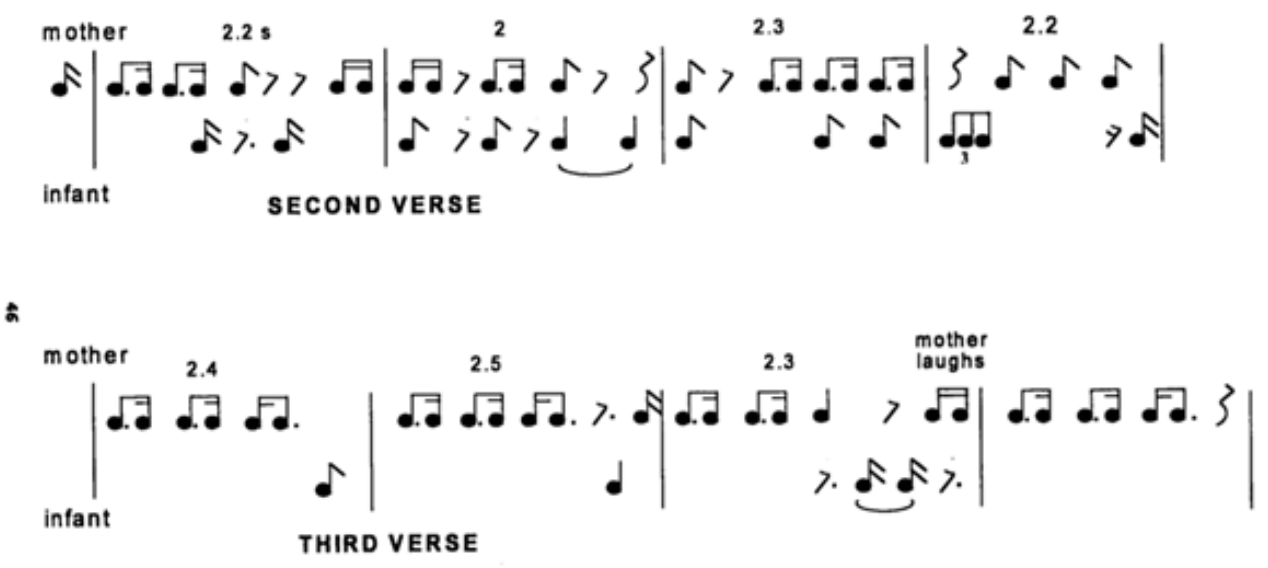

Fig. 1 - Notação musical que representa a participação da mãe e do bebê (quatro meses de idade) em um ritmo derivado da rima infantil Clap-a-clap-a-handies (os restos são omitidos onde isso não cause ambiguidade) (MALLOCH, 1999, p. 46).

A musicalidade comunicativa que perpassa essa relação mostra que mãe e filha são parceiras no diálogo que se concretiza através do pulso, da qualidade vocal e do tempo compartilhado, tão bem explorados no gráfico analisado. O autor chama a atenção para o fato de que o bebê foi capaz de entrar na "estrutura" do jogo musical com o outro, participando de maneira coordenada e lógica. As vocalizações e as rimas formam um sentido musical que segue a estrutura da rima, sem se opor a ela.

Além do caráter narrativo desse episódio, gostaria de destacar o detalhe observado no estudo de Beebe et al. (1988), referido na introdução deste artigo, qual seja, a combinação de turnos de conversa e silêncio, tal como ocorre na conversa entre adultos. A coerência vocal da narrativa flui nas trocas sucessivas e atinge um clímax com claro correlato afetivo. Como diria Daniel Stern, a mãe compartilha um estado afetivo, sente com seu bebê, como se entendesse o que ele quis expressar.

O conceito de musicalidade comunicativa como experiência vivida no momento presente aproveita as estruturas da experiência imediata para produzir sentido. Este parece ser o motivo do sorriso, considerado por Malloch o clímax da narrativa. A riqueza dessa experiência intersubjetiva é, segundo Stern, condição para a emergência do senso de eu e, por conseguinte, do senso de eu musical. 
A articulação que repercute em possibilidades para a Educação Musical pode ser apreendida a partir das palavras de Malloch (1999) e Stern (2007) na citação que segue. Os autores encontram nas narrativas musicais a essência da comunicação humana, em que os padrões que estruturam o tempo musical ao mesmo tempo estruturam a vida interior daqueles que participam do tempo compartilhado. Vejamos:

As narrativas de experiência individual e de companheirismo são construídas a partir das unidades de pulso e qualidade encontradas nos gestos criados em conjunto para as vocalizações e movimentos corporais. As narrativas são a própria essência da companhia humana e da comunicação. As narrativas permitem que duas pessoas compartilhem um senso de passar o tempo, criar e compartilhar as estruturas emocionais que evoluem através do tempo compartilhado. (MALLOCH, 1999, p. 45). ${ }^{6}$

O ponto essencial é que, quando se movem sincronicamente ou em coordenação temporal, as pessoas estão participando de um aspecto da experiência do outro. Estão vivendo parcialmente a partir do centro do outro. (STERN, 2007, p. 103).

Com base nas pesquisas referidas neste artigo, percebemos que os bebês são capazes de compartilhar emoções, sons, gestos, movimentos e significados; são sensíveis e produzem narrativas ajustando-se a um tempo comum, expressando prazer no contato social. Dois aspectos merecem destaque: o papel da experiência subjetiva organizadora do momento presente e o caráter intersubjetivo das experiências musicais vividas com o outro. O primeiro implica a possibilidade da formação de um senso de eu sem a necessidade de estruturas simbólicas, uma vez que as estruturas da experiência imediata são capazes de gerar sentido às experiências em curso. A pouca idade dos bebês, portanto, não é motivo para privá-los dos benefícios de uma educação musical apoiada em formas interpessoais de musicalidade comunicativa. O segundo aspecto valoriza o espaço interativo eu com o outro criado pela música, como condição para o desenvolvimento da musicalidade, por conseguinte, da identidade musical das crianças aspecto tão caro à Educação Musical.

Instigada pelas questões levantadas por Imberty (2008) na introdução deste artigo, sigo pensando: se a narrativa estrutura a experiência humana do tempo e ao mesmo tempo estrutura a nossa experiência com a música, poderia a narrativa musical explicar a natureza da nossa relação com a música?

\footnotetext{
$6 \quad$ "Narratives of individual experience and of companionship are built from the units of pulse and quality found in the jointly created gestures of vocalisations and bodily movement. Narratives are the very essence of human companionship and communication. Narratives allow two persons to share a sense of passing time and to o create and share the emotional envelopes that evolve through this shared time."
} 


\section{Referências}

BARRETT, Margaret. Attending to "culture in the small": A narrative analysis of the role of play, thought and music in young children's world-making. Research Studies in Music Education, v. 38, n. 1, p. 41-54, 2016.

BEEBE, B.; ALSON, D.; JAFFE, J.; FELDSTEIN, S.; CROWN, C. Vocal Congruence in Mother-Infant Play. Journal of Psycholinguistic Research, v. 17, n. 3, p. 245-259, 1988.

DISSANAYAKE, Ellen. Ethology, interpersonal neurobiology, and play. Insights into the evolutionary origin of the arts. American Journal of Play, v.9, n. 2, p.143-168, 2017.

Antecedents of the temporal arts in early mother-infant interaction. In: NILS, L. Wallim; MERKER, Björn; BROWN, Steven (Eds.). The Origins of Music. Cambridge, MA: MIT Press, 2001. p. 389-410.

. The earliest narratives were musical. Research Studies in Music Education, v. 34, n. 1, p. 3-14, 2012.

FERNALD, Anne; SIMON, Thomas. Expanded intonation contours in mothers' speech to newborns. Developmental Psychology, v. 20, n. 1, p. 104-113, 1984.

FERNALD, Anne. Four-month-old infants prefer to listen to "motherese". Infant Behavior Development, v. 8, p. 181-195, 1985.

HARGREAVES, D. J.; MACDONALD, R.; MIELL, D. Musical identities mediate musical development. In: MCPHERSON, G \& WELCH, G. (Eds.). Oxford Handbook of Music Education. V. 1. Oxford: Oxford University Press, 2012. p. 125-142.

IMBERTY, Michel. Narrative, splintered temporalities and the unconscious in 20th century music. Musicae Scientiae, Special Issue, p. 129-146, 2008.

KIRSCHNER, S.; TOMASELLO, M. Joint music making promotes prosocial behavior in 4-year-old children. Evolution and Human Behavior, v. 31, p. 354-364, 2010.

MALLOCH, S.; TREVARTHEN, C. (Eds.). Communicative musicality: Exploring the basis of human companionship. Oxford, UK: Oxford University Press, 2009.

MALLOCH, S. Mothers and infants and communicative musicality. Musicae Scientiae, Special Issue, p. 29-57, 1999-2000.

MAFFIOLETTI, L. A. Aprendizagens sociais propiciadas pela música na infância. In: SAN- 
TIAGO, D.; BROOCK, A.; CARVALHO, T. (Orgs.). Educação Musical Infantil. Salvador: PPGMUS-UFBA, 2011. p. 60-73.

MAFFIOLETTI, Leda de A. A música e as primeiras aprendizagens da criança. In: FLORES, Maria Luiza Rodrigues e ALBUQUERQUE, Simone (Orgs.). A implementação do PROINFÂNCIA no Rio Grande do Sul. Perspectivas politicas e pedagógicas. Porto Alegre: EdiPUCRS, 2014. p. 119-126. Disponível em: <http://ebooks.pucrs.br/edipucrs/Ebooks/ Pdf/978-85-397-0663-1.pdf>.

PAPAUŠEK, Hanuš. Musicality in infancy research: Biological and cultural origins of early musicality. In: DELIĖGE, I.; SLOBODA, J. (Eds). Musical Beginnings. Origins and development of musical competence. 2. ed. Oxford: Oxford University Press, 2000. p. 37-55.

STERN, Daniel. Diário de um bebê. O que seu filho vê, sente e vivencia. Tradução Daise Batista. Porto Alegre: Artes Médicas, 1991.

STERN, Daniel. Forms of Vitality. Exploring dynamic experience in psychology, the arts, psychotherapy, and development. Oxford: Oxford University Press, 2010.

STERN, Daniel. O momento presente na psicoterapia e na vida cotidiana. Tradução Celimar de Oliveira Lima. Rio de Janeiro: Record, 2007.

STERN, Daniel. Putting time back into our considerations of infant experience: a microdiachronic view. Infant mental health journal, v. 21, n. 1-2, p. 21-28, 2000.

STERN, Daniel. O mundo interpessoal do bebê. Uma visão a partir da psicanálise e da psicologia do desenvolvimento. Tradução Maria Adriana Veríssimo Veronese. Porto Alegre: Artmed, 1992.

STILL face experiment. Dr. Edward Tronick. Vídeo. Duração: 2'49". Infant-Parent Mental Health Program. ZERO TO THREE. Disponivel em: <https://www.youtube.com/watch?$v=a p z X G E b Z h t 0 \& t=9 s>$. Acesso em: 23 set. 2017.

TREVARTHEN, C.; DELAFIELD-BUTT, J. T. Intersubjectivity in the imagination and feelings of the infant: Implications for education in the early years. In: WHITE, Jaine; DALLI, Carmen (Eds.). Under-three year olds in policy and practice. New York: Springer, 2017. p. 17-40.

TREVARTHEN, C.; AITKEN, K. Infant Intersubjetivity, research theory, and clinical application. Journal of child psychology and psychiatry, v. 42, n. 1, p. 3-48, 2001. 